\title{
How perceptions of community environment influence health behaviours: using the Analysis Grid for Environments Linked to Obesity Framework as a mechanism for exploration
}

\author{
L. M. Nieuwendyk, MSc (1); A. P. Belon, PhD (1); H. Vallianatos, PhD (2); K. D. Raine, PhD (1); D. Schopflocher, PhD (1); \\ J. C. Spence, PhD (3); R. C. Plotnikoff, PhD (3,4); C. I. Nykiforuk, PhD (1)
}

This article has been peer reviewed.

Tweet this article

\begin{abstract}
Introduction: Overweight and obesity are influenced by a complex interplay of individual and environmental factors that affect physical activity and healthy eating. Nevertheless, little has been reported on people's perceptions of those factors. Addressing this critical gap and community partner needs, this study explored how people perceived the influence of micro- and macroenvironmental factors on physical activity and healthy eating.

Methods: Community partners wanted the study results in a format that would be readily and easily used by local decision makers. We used photovoice to engage 35 community members across four municipalities in Alberta, Canada, and to share their narratives about their physical activity and healthy eating. A combination of inductive and deductive analysis categorized data by environmental level (micro vs. macro) and type (physical, political, economic, and sociocultural), guided by the Analysis Grid for Environments Linked to Obesity Framework.
\end{abstract}

Results: Participants conceptualized health-influencing factors more broadly than physical activity and healthy eating to include "community social health." Participants spoke most often about the influence of the microenvironment ( $n=792$ ANGELO Framework coding tallies) on their physical activity, healthy eating and community social health in comparison to the macroenvironment $(n=93)$. Photovoice results provided a visual narrative to community partners and decision makers about how people's ability to make healthy choices can be limited by macroenvironmental forces beyond their control.

Conclusion: Focussing future research on macro- and microenvironmental influences and localized community social health can inform practice by providing strategies on how to implement healthy changes within communities, while ensuring that research and interventions echo diverse people's perceptions.

Keywords: environment, photovoice, ANGELO Framework, physical activity, eating behaviour

\section{Introduction}

Prevalence of overweight and obesity is growing at an alarming rate, with the number of adults with body mass index equal to or greater than $25 \mathrm{~kg} / \mathrm{m}^{2}$ increasing from 857 million worldwide in 1980 to
2.1 billion in $2013 .{ }^{1}$ These escalating rates of overweight and obesity are of concern given their association with a number of chronic diseases ${ }^{2,3}$ and significant economic burdens, particularly within health care systems. ${ }^{4}$ This increasing prevalence can be attributed to multiple
Highlights

- Since overweight and obesity are influenced by a complex interplay of individual and environmental factors that affect physical activity and healthy eating, this study, which used photovoice, reports on people's perceptions of those factors.

- Participants identified microenvironment settings (e.g. homes, schools, workplaces) more often than broader macroenvironmental influences (e.g. public and private sectors) as affecting their physical activity and healthy eating.

- At the microenvironment level, participants most often described the physical environment as shaping their ability to be physically active.

- When participants talked about healthy eating, they described the influence of the sociocultural and economic environments as almost equal to that of the physical environment.

- Participants conceptualized healthinfluencing factors more broadly than physical activity and healthy eating to include "community social health."

- Photovoice allowed local decision makers to see how residents perceived their local community environments from a visual and narrative perspective.

individual-level factors (e.g. age and sex) and environmental features (e.g. 
including physical, economic, sociocultural and political environments) ${ }^{5,6}$ that affect physical activity and food consumption.

Historically, public health practitioners have sought to identify a single cause for the complex factors that contribute to obesity. ${ }^{7}$ This narrow focus has recently evolved to include the study of complex interactions between the behaviour of people and their environments. ${ }^{5,8,9}$ Socioecological approaches recognize that health behaviours (i.e. unhealthy eating and physical inactivity) that contribute to the development of obesity are a result of larger social systems ${ }^{10}$ typically beyond people's control. This interplay between people and their environments reveals potential new approaches to interventions. ${ }^{11,12}$ People are affected by their interactions with other people, organizations and policies in their communities; thus, influencing factors at each ecological level will help foster the development of environments that support physical activity and healthy eating. ${ }^{13}$

The complex interactions of the various environmental factors that influence obesity are referred to as "obesogenic environments." 5 The obesogenicity of an environment can be defined as the sum of a multiple set of conditions that constrains people to adopt a healthy diet and active lifestyle. ${ }^{5}$ The dynamic, multilevel nature of obesogenic environments creates operational difficulties for practitioners, decision makers and researchers who are seeking opportunities to prevent and reduce obesity. ${ }^{12}$ Despite these challenges, many experts agree that broader policy and environmental changes have the greatest potential for improving population health and are best suited to addressing the complexity of obesogenic environments. ${ }^{14,15}$

Still, there is a relative paucity of literature on perceptions of how multiple environmental levels influence physical activity and healthy eating behaviours, a critical perspective given the influence of environments on obesity. ${ }^{5,10}$ Among socioecological approaches, ${ }^{6}$ the ANGELO (ANalysis Grid for Environments Linked to Obesity) Framework recognizes two levels of environment: ${ }^{5}$ the microenvironment setting, which includes places where people or groups gather for specific purposes, for example, homes, workplaces or schools, and the macroenvironment sector, which includes the broader environment influenced by public and private sectors, such as groups of industries and services. Within the micro- and macroenvironments, the ANGELO Framework includes four types of environment: physical (what is available); political (what are the rules); economic (what are the costs); and sociocultural (what are the attitudes and beliefs). ${ }^{5}$ Some examples of how different environmental levels influence physical activity and eating behaviours within the ANGELO Framework include

- Macrosociocultural environment: advertisements of high-fat foods on television during sporting events;

- Microsociocultural environment: local role models advocating for eliminating sugar-sweetened beverages in school settings;

- Macropolitical environment: governmental regulation of the construction of sidewalks in new residential developments;

- Micropolitical environment: parental restriction on children walking or bicycling to the local recreation facility;

- Macrophysical environment: a network of bike lanes in a community;

- Microphysical environment: neighbourhood yards kept up with flowers, shrubs and trees;

- Macroeconomic environment: prices of food and drink at a fast-food chain; and

- Microeconomic environment: an indoor walking track available to seniors for free.

Understanding how people perceive these environmental levels and types can help clarify what environmental attributes affect health. We can use this information strategically to promote physical activity and healthy eating and to get a nuanced public health understanding of how elements of obesogenic environments influence behaviour.

The objective of this project was to understand people's perceptions of the influence of micro- and macrolevel community environmental factors on physical activity and healthy eating, that is, elements that are significant in characterizing obesogenic environments and identifying appropriate local intervention.

\section{Contextual background}

This project was one phase of Community Health and the Built Environment (CHBE), a larger research project investigating the integrated role of built and social environments in community interventions for obesity and chronic disease prevention. ${ }^{16}$ CHBE was a three-year (2007-2010) project that took place in four communities in Alberta, Canada. The researchers worked closely with community partners (key stakeholders from each community) to collaborate on developing and implementing the project. We used a communitybased, participatory approach to ensure that project results were relevant for community policy and practice as well as for research.

\section{Methods}

We used photovoice ${ }^{17}$ to understand people's perceptions of their physical activity and healthy-eating environments while engaging community members and building support for environmental change. In this approach, participants are asked to take photographs of their community and to then share their stories about those photographs. ${ }^{18}$ The photo-stories have the potential to elicit critical discussion on community issues by providing an array of visual and narrative data that can be shared with key decision makers and other community stakeholders. ${ }^{18} \mathrm{We}$ decided that photovoice was the best methodology because community partners had identified the importance of visual representations for decision makers (rather than the purely narrative data that would be obtained through interviews or focus groups).

\section{Setting}

Four communities were involved in this study. St. Paul and Bonnyville are two smaller rural municipalities in northern Alberta, each with a population of about 6000 , serving larger populations of 10000 from surrounding communities. ${ }^{19,20}$ St. Paul has a rich agricultural tradition, while Bonnyville serves the oil and gas industry. ${ }^{19,20}$

North Central Edmonton, an urban innercity community, comprises 11 neighbourhoods (with a total population of 41026$)^{21}$ within the urban core of the city of Edmonton, in the northern half of Alberta. Medicine Hat and its suburb, Redcliff, are urban communities in the southernmost part of Alberta. Medicine Hat is a large urban municipality (population of 61 097). ${ }^{22}$ Major sources of industry 
include agriculture, manufacturing, and oil and gas. Redcliff borders Medicine Hat and shares a large number of resources and services with the larger municipality. These communities were selected as a continuation of previous community-university partnership research on chronic disease prevention. ${ }^{16,23,24}$

\section{Participants}

In the spring of 2009 , between 7 and 10 residents from each of the four communities were recruited to participate in the study. In total, 35 participants took part, which was enough to reach data saturation. Of these, $74.3 \%$ were women; $71.4 \%$ were 35 years or older; and $40 \%$ reported an annual household income of less than $\$ 50,000$. A variety of mechanisms were used to recruit the general population as well as minority or harder-to-reach populations: via local newspaper articles, posters at key locations such as community centres and local libraries, and word-ofmouth and mass emails through local partner organizations such as family and community service agencies, not-for-profit organizations and local government. To be eligible for the study, participants had to be 16 years or older, live in the community, and be willing to commit 4 to 5 hours over a few weeks to participate in interviews conducted in English.

Research ethics approval was obtained from the Health Research Ethics Board (Panel B), University of Alberta, prior to the start of this project.

\section{Data collection}

The participants took part in a one-on-one in-person semi-structured interview to find out their perceptions of community, physical activity and healthy eating. The interviews, conducted by a trained research assistant familiar with the community, lasted about 60 minutes. The primary purpose of the first interview was to build rapport with participants while a secondary purpose was to gain an initial understanding of the local community. At the end of this interview, participants were provided with a digital camera and shown how to operate it. They then had two weeks to take photographs with a "focus on things in your community that make it easier or harder ... to be physically active and eat healthy foods." To minimize the researchers' influence, the directions were loosely structured, allowing participants to take photographs of whatever they felt influenced their physical activity and healthy eating.

The developed photographs were returned to the participants, who met with a research team member for one-on-one inperson semi-structured interviews at a central community location (e.g. local library). ${ }^{24}$ These in-depth follow-up interviews gave the study participants a chance to share the stories behind their photographs. The participants selected the most meaningful and representative photographs for discussion in the interview and described why they took that particular photo. Further questions led to understanding the association between the photo content and physical activity and/ or healthy eating. The photographs were discussed until the allotted time of 90 minutes was reached to respect the participants' time; each participant discussed an average of 13 photographs. Interviews were audio-recorded.

The interviews were conducted to gain a greater understanding of individual and community issues important to each participant ${ }^{24}$ by eliciting a variety of stories across each community and exploring each story in-depth. The research team and community partners determined that focus groups, which are often used in photovoice projects, ${ }^{17,18}$ could jeopardize the depth of data shared by participants, particularly given the potential breadth of this study topic. Further, the community partners identified a critical need to elicit a vivid story of participants' experiences and their identification of detailed perceptions on community-specific topics to support local decision making and future public health action.

\section{Analysis}

The combination of visual and narrative results stemming from photovoice methodology lends itself well to dissemination among local decision makers and stakeholders. ${ }^{17}$ This methodology also allowed our community partners to present the study data and findings in a format that would be readily used by local decision makers. To facilitate knowledge translation to the community, we used the ANGELO Framework ${ }^{5}$ during data analysis to systematically explore participants' perceptions of community environments. This framework was deemed appropriate for this study as it has been used before to help identify areas for intervention, ${ }^{25}$ and to conceptualize obesogenic environments and organize data. ${ }^{12,26}$

All interviews were transcribed and coded using NVivo10 qualitative software version 10 (QSR International Pty Ltd., Melbourne, AUS). As the purpose of this analysis was to examine people's perceptions of micro- and macrolevel environmental influences elicited by the participants' photo-stories, coding focussed on the follow-up interview. In the follow-up interviews, participants reflected on the photographs they had selected and, with those as context, discussed how their community environments influenced their physical activity and healthy eating behaviours. Following this elicitation approach, the selected photographs were used to support the analysis of the interviews to help illustrate the context of the participants' narratives.

Photovoice methodology recommends that data is analyzed with the participants. ${ }^{17,18}$ In this project, that critical stage of analysis occurred during the follow-up interview where participants led the analysis of their photographs, assigning meaning to the images and explaining the meaning to the interviewer. ${ }^{24}$ The interview guide was used, as needed, to spur conversation, but its primary focus was to capture the main ideas behind each photograph and elicit meaning rather than lead the participant to a specific insight. After all the interviews had been completed, the researchers undertook a second, organizational stage of analysis where the meaning identified by the participants was categorized into broader themes, guided by the ANGELO Framework. This staged approach retained the participants' active role in revealing meaning, while respecting the time they committed to participating in the phototaking exercise and two in-depth interviews. While the participants were not included in the second stage of data analysis, they were invited to review and revise summaries of their quotes for the photographs selected to represent broader categories and themes to be included in reports of study findings and presented at community events and beyond. Participant review of the revised summaries helped the researchers confirm the categorization of excerpts and themes within the ANGELO Framework. 
To facilitate categorization of data during the second stage of analysis, the interview transcripts were initially double-coded by two trained researchers using an inductive coding scheme that retained the meaning explained by the participants. The use of an initial inductive approach to coding allows for themes to be considered independently of the complexity of the interrelationships between environment types. Next, the researchers identified excerpts from the transcript that fell within one or more of the four environment types: physical, economic, political and sociocultural. Specifically, excerpts were deductively assigned into micro- and macroenvironmental levels using a coding scheme; examples presented by Swinburn et al. ${ }^{5}$ were used as a conceptual guide. The excerpts were then further classified into physical activity and healthy-eating categories. A third category, "community social health," which comprised indirect influences on participants' physical activity and healthy eating, emerged from the participants' narratives during coding.

Following coding, we assessed the extent of coder agreement. Given the intentionally multidisciplinary nature of the research expertise on the coding team (i.e. anthropology, nutrition, health promotion, physical activity), $100 \%$ consistency was neither expected nor sought; rather the intent was to determine the extent of coding overlap. In cases of coder agreement, the code was assigned a numeric score of one. Excerpts on which original coders did not agree were scored as 0.5. Scores were tallied to provide a descriptive representation of the participants' perceptions of community environment types (physical, political, sociocultural and economic) and levels (micro and macro) with respect to physical activity, healthy eating, and community social health.

\section{Results}

Participants were invited to describe the environmental influences in their physical activity and healthy eating behaviours, but they also talked about other healthrelated behaviours. Specifically, they discussed how everyday broader characteristics of the community environment encountered in everyday life affected their well-being and quality of life, implicating a relationship between positive states of well-being/quality of life with the enhanced capacity to take positive steps towards their own health. Participants' perceptions and thoughts on these broader characteristics make up the category "community social health." For example, some participants spoke about the importance of the local library (an element of the microphysical environment) in providing an opportunity for positive mental activity for all residents, but especially older adults. When asked how a photograph of a birdhouse in her backyard was related to her health, a participant explained: "[it is] very calming, very pleasing ... definitely enjoyable” (microsociocultural environment). In another example, a participant suggested that local business initiatives for women indirectly improve the community (microeconomic environment). In these examples, the local library, the birdhouse and the local bursary program do not directly relate to individual- or community-level physical activity or healthy eating, but are critical as participants perceived them as important contextual elements for those "healthy" behaviours and their overall well-being. (See Tables 1 and 2 for representative quotes about the microenvironment settings and macroenvironment sectors, respectively, by environment types and the physical activity, healthy eating, and community social health categories.)

Figure 1 summarizes the coding tallies according to the ANGELO Framework. Participants spoke most often about the influence of the microenvironnment ( $\mathrm{n}=792$ coding tallies) on their physical activity ( $n=323.5$ coding tallies), healthy eating ( $n=114.5$ coding tallies) and community social health $(\mathrm{n}=354$ coding tallies).

Within the microenvironment, participants most often described the physical environment (323.5 coding tallies) as shaping their ability to be physically active: the physical infrastructure in their community, from parks, indoor recreation facilities and public swimming pools to sidewalks, crosswalks and shaded areas. In contrast, with respect to healthy eating, they spoke to almost the same degree about the various influences of physical (e.g. availability of grocery stores and cafeterias), sociocultural (e.g. social gatherings involving food and supporting local food businesses) and economic (e.g. affordable pricing in supermarkets) microenvironments on their food behaviours. For example one participant spoke about the relevance of the availability (microphysical environment) and aesthetics (microsociocultural environment) of healthy food in grocery stores: "The vegetable displays and the selection we have available are excellent. I don't understand why so many people buy junk food. I think the community is well served by the local grocery stores for healthy food options” (see Figure 2).

The influence of the economic environment on the three categories was highlighted equally among participants. Participants mentioned the concurrent influence of the microeconomic environment on physical activity, healthy eating and community social health, suggesting that financial costs influence people's decisions to be physically active and/or eat healthy food and affect the social health of their community. For instance, the high costs associated with accessibility to local recreation facilities and to a diet rich in vegetables and fruits was mentioned as a restriction on people's abilities to adopt healthy behaviours. Despite this, almost all of the other categories were discussed more frequently than the microeconomic environment, implicating economics as a relatively straightforward foundational element relative to the more complicated interplay of physical, sociocultural and political factors that influence people in potentially more subtle ways.

This complex, subtle interplay may explain why the micropolitical environment was rarely revealed in the healthyeating category. For instance, only a few participants mentioned micropolitical environmental factors such as family rules or local school policies about healthy eating, as described here: "We had a couple [of vending machines], but I think the school decided to replace them with ... more healthy ones."

In contrast, a common, shared microsociocultural theme across the three categories was social interactions. The opportunity to meet people in the community and strengthen their social connections with others was perceived by participants as affecting their physical activity, healthy and unhealthy eating, and community social health. For instance, a participant talked about a nocost physical activity opportunity in his community and added: "[The Taekwondo class] is wonderful for us, but better than 
TABLE 1

Sample quotes about the microenvironment setting, by category (physical activity, healthy eating and community social health) and environment type, according to the Analysis Grid for Environments Linked to Obesity (ANGELO) Framework

\begin{tabular}{|c|c|c|}
\hline & & Microenvironment setting ${ }^{\text {a }}$ \\
\hline \multirow[t]{4}{*}{ Physical activity } & Physical environment & $\begin{array}{l}\text { "[The trees on the streets] are very beautiful, and it looks so nice and shady and cool. I like taking the shady } \\
\text { routes on hot days." }\end{array}$ \\
\hline & Economic environment & $\begin{array}{l}\text { "The walking track [in the gym] is available for seniors free ... That is somewhere that I can go and it doesn't cost } \\
\text { anything." }\end{array}$ \\
\hline & Political environment & "The hours that you can swim [at the lake] are limited." \\
\hline & Sociocultural environment & “[My bike] is the best, easiest way to get around where [I] live ... it is just a huge part of my local life.” \\
\hline \multirow[t]{4}{*}{ Healthy eating } & Physical environment & “[Name of grocery store redacted] is an asset [to] the community, and they promote local food." \\
\hline & Economic environment & "Growing your own vegetables ... you know the benefits that you get from that as well as ... reducing the cost ..." \\
\hline & Political environment & $\begin{array}{l}\text { "I think a lot is dictated [by] what kids want. Like when I am with my friends the first thing they will ask is where } \\
\text { the kids want to eat." }\end{array}$ \\
\hline & Sociocultural environment & $\begin{array}{l}\text { "We are eating out too much, way more than I thought ... but yes, I think ... the eating out ... [gives us] a lot of } \\
\text { social time ... with other people." }\end{array}$ \\
\hline \multirow[t]{4}{*}{$\begin{array}{l}\text { Community } \\
\text { social health }\end{array}$} & Physical environment & $\begin{array}{l}\text { "I think the library is a great asset to the town and particularly to seniors.... They have just renovated that library } \\
\text { and made it very nice." }\end{array}$ \\
\hline & Economic environment & "There are bursaries available for women who want to set up a business.... [The neighbourhood] is getting a lot better." \\
\hline & Political environment & "Graffiti is one thing that is illustrative of problems that need deeper solutions than they are getting." \\
\hline & Sociocultural environment & $\begin{array}{l}\text { "So much of what gets me out of the house and into the community is chatting with the neighbours and getting } \\
\text { to know people and building a safer, stronger, unified group of people in the neighbourhood." }\end{array}$ \\
\hline
\end{tabular}

${ }^{a}$ Includes places where people or groups gather for specific purposes, e.g. home, workplaces, schools.

that is the social connection. The parents that I have met in there and connected with and the kids that I have met in there and connected with are people that wouldn't normally be in my social circle ... and I think that hopefully I would be a role model for kids as well."

The influence of macroenvironments ( $\mathrm{n}=93$ coding tallies) on participants' physical activity $(\mathrm{n}=43)$, healthy eating ( $\mathrm{n}=4$ ) and community social health ( $\mathrm{n}=46$ ) was mentioned far less often than that of microenvironments (Figure 1), especially when discussing healthy eating. Participants referred to the influence of the macropolitical environment on physical activity and community social health most frequently. They mentioned governmental health policies that aim to promote the well-being of the general population. Most described how local government policies and programs affected their ability to be physically active in their community, as exemplified by one participant: "We don't have a city councillor ... specific to this neighbourhood, so then you just have to pick one out of the blue ... I have emailed [them] about physical activity things and [they] have never done anything about it." When raised by participants, the macropolitical environmental factors concerning (un)healthy eating encompassed policies such as the provincial government's on healthy eating in schools and farmers' markets food regulations.

Many participants referred to how they did not feel they had control over the political climate in their local communities; for example, when reflecting on the macrophysical environment influencing physical activity, one participant noted that: "there [are] a lot of old sidewalks that are in very bad repair.... [We] have complained about it [to town council, but] it has pretty much fallen on deaf ears" (see Figure 3). Similarly, a macrophysical environmental factor to do with healthy eating was the lack of a bicycle network, which was described as affecting access to grocery stores by those without a car. The lack of a public transportation system (in rural communities) was also described as a factor affecting people's abilities to be mobile and reach food outlets (macrophysical environment for healthy eating) and community services in general (macrophysical environment for community social health).

Participants described a wide array of examples of macroeconomic environmental factors, including the public investment in physical activity infrastructure such as bike paths/sidewalks, the pricing strategies adopted by fast-food corporations and financial support from municipal governments to promote community assets such as greenhouses. Macrosociocultural environmental factors included policies to promote a culture of traffic safety for drivers, pedestrians and cyclists (physical activity); campaigns and advertisments of fast-food corporations to increase consumption (healthy eating); and zoning bylaws and landscaping regulations (community social health).

Using the ANGELO Framework to organize how participants conceptualized their physical activity and healthy eating in their community with respect to the different environment types and settings was critical for the sharing of information back to decision makers in the communities. For this aspect of the project, each community determined the best way to meaningfully engage decision makers and the general public in the display of the results. This included presentations to council, static displays at local libraries, interactive community map displays, PechaKucha style presentations at local farmers' markets or community events, and hard-copy and electronic summary reports that were shared with local decision makers and community practitioners. The changes that were facilitated in each community as a result of this dissemination were unique. For example, in one community the 
TABLE 2

Sample quotes about the macroenvironment sector, by category (physical activity, healthy eating and community social health) and environment type, according to the Analysis Grid for Environments Linked to Obesity (ANGELO) Framework

\begin{tabular}{|c|c|c|}
\hline & & Macroenvironment sector ${ }^{\mathrm{a}}$ \\
\hline \multirow[t]{4}{*}{ Physical activity } & Physical environment & $\begin{array}{l}\text { "It is just pure scary going across that bridge when there [are] trucks coming by you at } 80 \text { to } 90 \text { kilometres per } \\
\text { hour.... People are afraid to cycle.... I have spoken to the department of highways ... but no changes have been } \\
\text { made yet." }\end{array}$ \\
\hline & Economic environment & “The city only invested $\$ 35,000$ for the on-road bike lane program." \\
\hline & Political environment & $\begin{array}{l}\text { "[The sidewalks have been] left out because this was a town subdivision; this wasn't a separate commercial } \\
\text { venture by a land owner. This was the town's own design and they didn't put sidewalks in.” }\end{array}$ \\
\hline & Sociocultural environment & $\begin{array}{l}\text { "So [the town] is working to make the crosswalk, designed crosswalks more recognizable so people will actually go } \\
\text { a few yards or metres over to get to it. So I think the streetscape design [creating a culture of safety] is going to } \\
\text { really help as far as pedestrians getting across safely." }\end{array}$ \\
\hline \multirow[t]{4}{*}{ Healthy eating } & Physical environment & $\begin{array}{l}\text { "There is a large population of [name of ethnic group redacted] in the community and they can't drive, so they } \\
\text { are trapped, really trapped in the community. [The municipality has] talked about putting in a bike path for them } \\
\text { to get to the larger city safely ... but this has not happened yet." }\end{array}$ \\
\hline & Economic environment & $\begin{array}{l}\text { "[Name of fast-food chain] encourages you to eat more. Two litres of pop for only a few pennies more than a few } \\
\text { ounces of pop ... They are encouraging you to eat more than you need to or want to." }\end{array}$ \\
\hline & Political environment & $\begin{array}{l}\text { "[Licensing boards] have stricter rules for farmers' markets than they do for stores ... Everything has to be } \\
\text { inspected.” }\end{array}$ \\
\hline & Sociocultural environment & $\begin{array}{l}\text { "[Name of fast-food chain] spent billions of dollars in advertising, and billions of dollars in research on, you } \\
\text { know, colour schemes and everything else that might entice you to eat more while you are there." }\end{array}$ \\
\hline \multirow[t]{4}{*}{$\begin{array}{l}\text { Community } \\
\text { social health }\end{array}$} & Physical environment & $\begin{array}{l}\text { "Today [the bus] went to one of the senior lodges and picked up a bunch of people that do not drive, [who] are } \\
\text { stuck in their places ... and took them to whatever they wanted to do... [This] is a really good thing that this } \\
\text { town has." }\end{array}$ \\
\hline & Economic environment & $\begin{array}{l}\text { "The greenhouses in the community have been having some financial troubles; they were trying to get some } \\
\text { money from the government to help support their businesses." }\end{array}$ \\
\hline & Political environment & $\begin{array}{l}\text { "The provincial government [is] trying to have people have a quality of life [with] less people ... in hospital and } \\
\text { emergency.... I think that the feds are doing it too, but the city here [is] stuck in a time warp, back a lot of years, } \\
\text { and it is unfortunate." }\end{array}$ \\
\hline & Sociocultural environment & $\begin{array}{l}\text { "I think [downtown] is the heart of our community.... I feel that [the town council] should put a bylaw that any } \\
\text { place in town, uptown should be presentable. Even [if] it is vacant you can make it look attractive without } \\
\text { spending a lot of money." }\end{array}$ \\
\hline
\end{tabular}

${ }^{\text {a }}$ Includes the broader environment influenced by public and private sectors, such as groups of industries and services.

display of the photographs and stories led to a municipal policy change to sidewalk/ trail maintenance programs, and in another the development and sustained implementation of a children/youth outdoor free play program. ${ }^{16}$

\section{Discussion}

In this section, we explore specific elements related to the macroenvironment sector and microenvironment setting. We then reflect critically on the implications of study results for future interventions that target community environments to promote health.

\section{Macroenvironment sector}

Our analysis suggested that participants did not readily recognize the influence of the macroenvironment on their physical activity and healthy eating behaviours and community social health (see
Figure 1). This lack of immediate recognition does not negate the influence that this sector can have on obesogenic behaviours, ${ }^{12}$ but reinforces the notion that those influences can be subtle, if not insidious. For example, participants rarely considered their eating behaviours to be shaped by macroenvironmental factors, which indicates an under- or distal awareness about the food industry and governmental influences on dietary options. Participants focussed on their immediate food environments, which were more directly within their locus of control, sharing their experiences with grocery stores and personal gardens. While these local embodiments of food are most obvious, public health practitioners should be concerned about building the public's recognition of the macroenvironmental factors, such as media and food production systems, that shape food-related decision making. ${ }^{12}$
In contrast to their consideration of healthy eating, participants more often mentioned the influence of macropolitical environments on the physical activity and community social health categories, easily describing the role of policies in creating supportive environments. The influence of the broad macroenvironments was discussed less frequently and in less depth than elements within the participants' microenvironments. This may be a function of the study's focus on "community," but also can be explained by the fact that researchers $^{12}$ and policy-makers ${ }^{27}$ have consistently paid more attention to individual approaches when analyzing and creating strategies to tackle obesity, especially through behavioural correlates of diet and activity. This emphasis on personal responsibility can be seen as blaming people for their choices, neglecting the reality that people's unhealthy choices are often shaped and constrained by 
FIGURE 1

Summary of the coding tallies, by type and level of environment and by category, according to the Analysis Grid for Environments Linked to Obesity (ANGELO) Framework

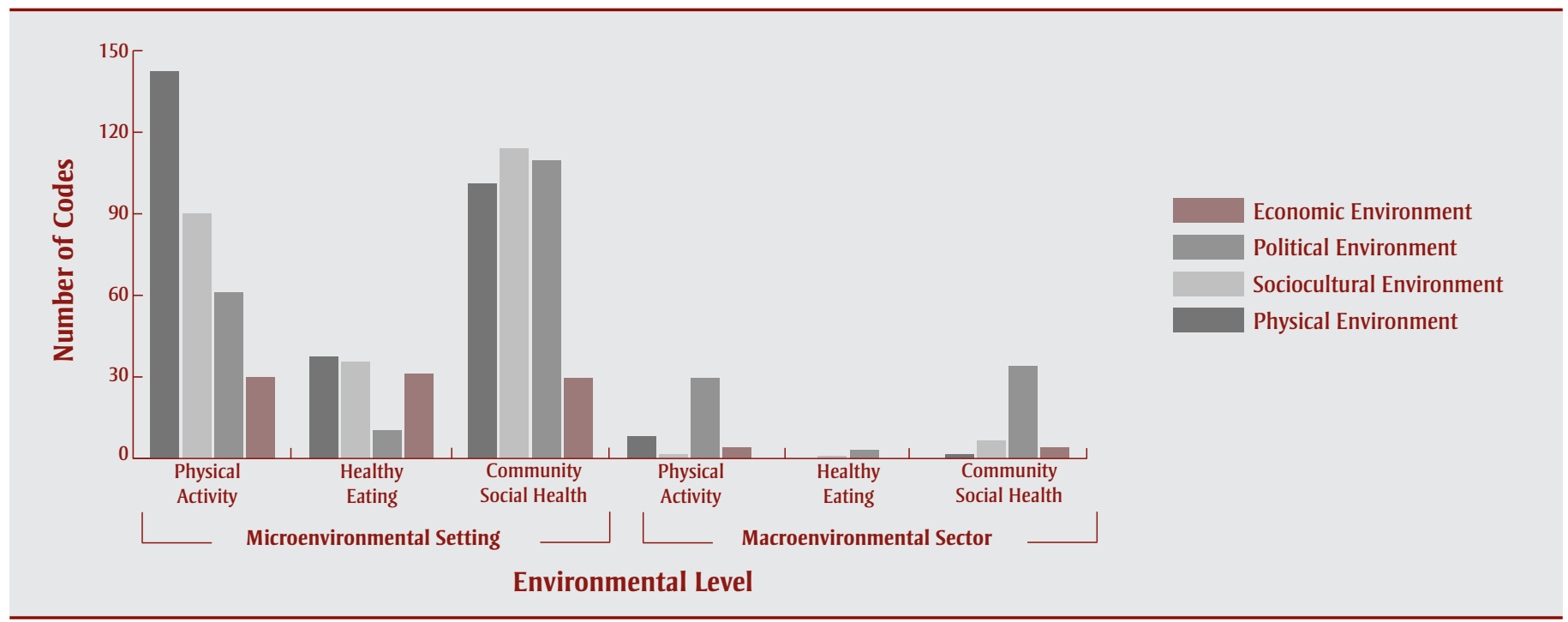

macroenvironmental forces ${ }^{5}$ that are created and propagated by societal milieu.

Advocating for action is something that may be within the reach of community residents, with impact at both micro- and macroenvironment levels, over a longer term. Through photovoice, policy advocacy could focus on engaging local governments to be more active in creating supportive community environments to prevent obesity and chronic disease. ${ }^{28}$ For instance, our project participants could

FIGURE 2

Participant's photograph of a shelf in the grocery store representing the microenvironment setting

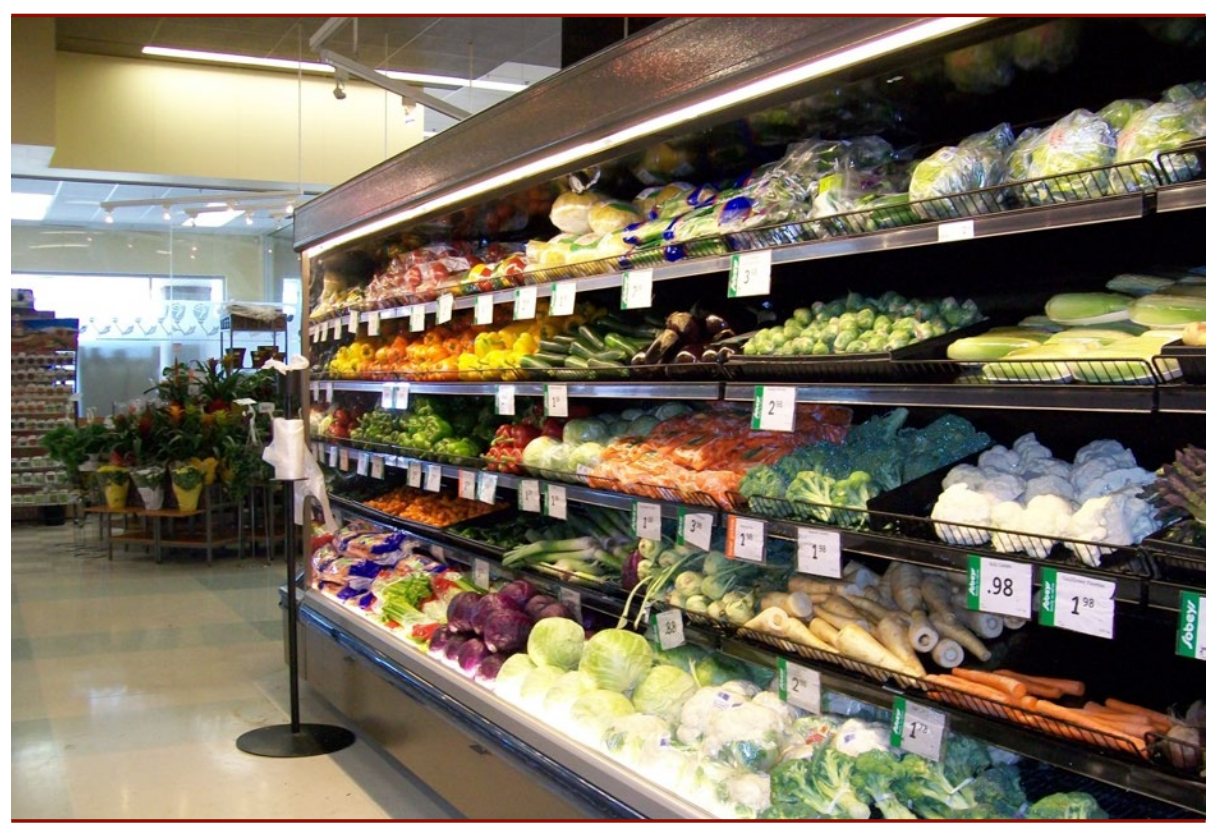

physical activity, healthy eating, and community social health. This may be due to many factors. First, they were asked to focus on their local communities and, thus, may have limited themselves to their microenvironment. Second, people are frequently inundated with information emphasizing the personal responsibility to make healthy choices. Researchers, governments and media messaging do not usually include the role of external factors in creating the obesogenic environment, and the general public is at the mercy of the knowledge accessible to them. Third, the microenvironment may have been where the participants felt the most locus of (perceived) control, ${ }^{2}$ which may have facilitated their identification of a greater number of influential factors.

How participants discussed the influence of the physical, sociocultural, political and economic environments on their physical activity, healthy eating and community social health varied greatly within the microenvironment setting. For the microeconomic environment, representation was consistent across categories, suggesting that socioeconomic factors pose critical barriers to physical activity, healthy eating and community social health. ${ }^{12,29}$ This suggests that public health policy should develop a variety of actions that focus on reducing socioeconomic barriers, ${ }^{14}$ such as decreasing the costs of healthy foods and subsidizing gym memberships for low-income families, allowing for comprehensive approaches to obesity prevention to be strengthened. Local rules 
FIGURE 3

Participant's photograph of a sidewalk in need of repair representing the macrophysical environment sector

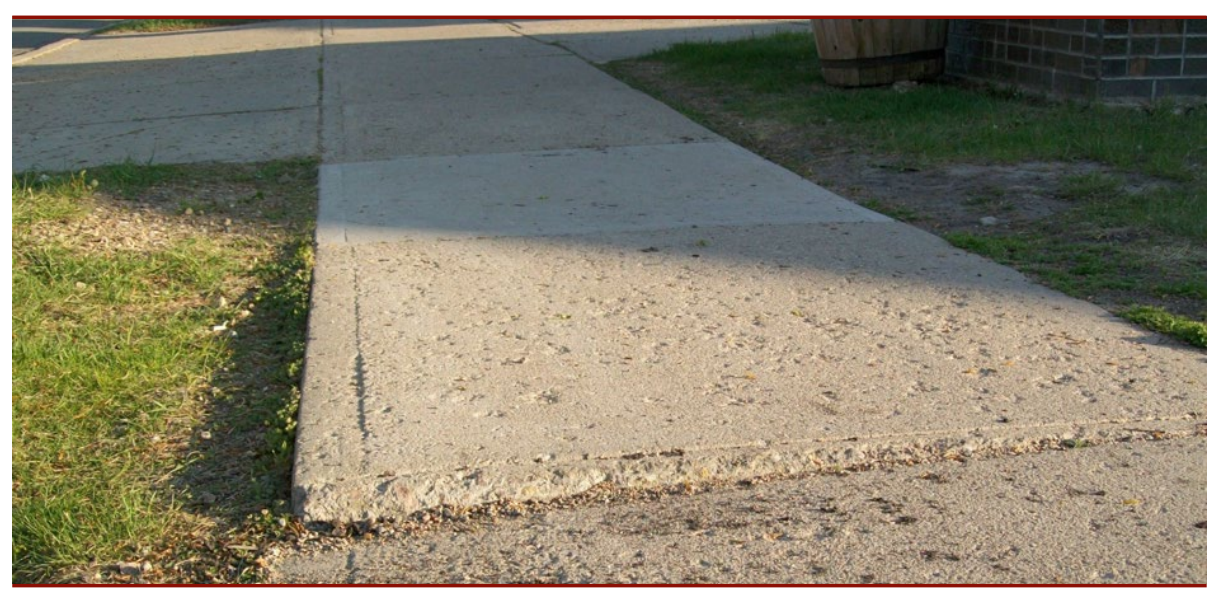

and regulations can also shape people's abilities to be healthy (micropolitical environment). ${ }^{14,15}$ For example, studies suggest that expanding hours of operation at recreation facilities and increasing local regulations (e.g. via neighbourhood associations) that ensure people's right to live in a safe, aesthetically pleasant, healthy environment have a positive effect on healthy behaviours. ${ }^{14,15}$

For the physical environment, participants often spoke about how the physical activity resources available in their community affected their ability to be active, which reinforces associations between infrastructure and active living found in previous studies. ${ }^{6,14}$ Finally, the sociocultural environment (e.g. cultural preferences and socialization with neighbours) was described as important to physical activity, healthy eating and community social health, findings that have been documented elsewhere. ${ }^{12,25}$ This underscores the need for careful and nuanced investigations of exactly how sociocultural environments constrain or encourage health-promoting behaviours and affect community social health. ${ }^{12}$

\section{Strengths and limitations}

This exploratory study was bounded by its methodological approach, including a purposeful overlap in coding for the different categories and environmental levels and types, resulting in some excerpts being double- or triple-coded to reflect the inherent complexity and interrelated nature of environmental forces relative to obesity. Some might argue that even if participants repeat things many times it does not necessarily mean it is important or that there is a deeper meaning in what they are saying; we do not feel that this is the case here, as meaning was assigned by participants and then reflected in the categorization of excerpts into thematic categories.

The relative quantity of themes populating each type and level of environment in this analysis could be misleading, and may suggest that the microenvironment settings predominate given that the large majority of themes fell in this category. This, however, may be a superficial assessment of the data. The participants were asked to photograph things in their environment that influence their abilities to be physically active and eat healthy food-and were asked to do this in a twoweek period. This is a relatively short time to internalize and complete the task, and do so in a way that captures the subtleties of environments. For participants, physical attributes seemed the easiest or most obvious to photograph, whereas capturing political environment features, for instance, may have required more time or thought. Yet, elements of the more intangible environments emerged during discussions around the participants' photographs, suggesting that the microenvironment settings and physical environment attributes were gateways to discussion-and potentially action-on the macroenvironment levels and the sociocultural, economic and political aspects of community environments relative to their health. While not all elements of the ANGELO Framework were readily captured in photographs, it was the rich pool of photovoice data that allowed for all elements of the ANGELO Framework to be populated with narrative interview data. As the interview progressed, many participants' stories transcended the original topic raised by the photo and invoked more complex threads of meaning.

Despite the study's small sample size, the results show interesting patterns in residents' perceptions of how community environments influence their physical activity and healthy eating behaviours. In addition, the themes evoked by the participants were similar across the communities, suggesting their relative importance in our society. Building on this exploratory study, future research should explore the differences in perceptions between different settings (e.g. urban versus rural communities) and population groups (e.g. seniors versus youth) to allow for more practical and settings-based recommendations for programs, policies and interventions. As is typical with deep, exploratory studies, generalizability of the findings is neither expected of nor appropriate for this work.

Although the project data was collected in 2009, these findings hold important implications for research and practice in obesity reduction and prevention. The ANGELO Framework is widely used in obesity and chronic disease prevention research. This study demonstrates how it can be used to inform and stimulate local health promotion as well as as an effective way to translate community knowledge. Presenting the community attributes by environment type and level allows researchers and decision makers to more clearly understand and picture how different elements of the community environment influence people's decisions about healthy behaviours and how local action can be tailored to address specific gaps and opportunities in the community.

\section{Implications for research and practice}

The project findings had immediate implications for the four participating communities when the photographs, stories and analysis were shared back with community partners, decision makers and community members through a variety of different mechanisms (e.g. formal council presentations, open houses at local libraries, community reports, etc.). They particularly helped local decision makers see from a visual and narrative perspective how residents perceived their community 
environments, something that could not have been possible with quantitative data alone. This sharing of the data led to local community action to address some of the issues raised by participants (e.g. a maintenance program for community trails). Photographs and narratives also showed the decision makers that the ability to make healthy choices can be limited by macroenvironmental forces that are beyond the people's control. Thus, in this community-based participatory research project, the results reinforced the decisive role of decision makers in providing supportive policies and infrastructure that encourage their community population to eat healthy food and be physically active.

While this study had important implications at a local level, the results raise two important questions that researchers, practioners and decision makers should consider more broadly when developing interventions, programs or policies that aim to improve community environments to support physical activity and healthy eating:

(1) Is there an implicit focus (in academia and civil society) on the microenvironment setting because that is what the public sentiment is driving?

The participants emphasized the effect that the microenvironment can have on their physical activity and healthy eating, which may stem from their understanding and interpretation of the common discourse on personal responsibility concerning these behaviours. ${ }^{27}$ While some people may embrace socialized "healthy" ideals, others resist them. Future systems-level research should seek to explore people's perceptions of the macroenvironment in greater depth to determine at what level the under-awareness of its effects is a function of the sociocultural (e.g. magazines and TV shows) and political (e.g. interventions targeting individuals or smalls groups) environmental forces. Systems-level research is needed to determine the reason for such a dedicated focus on the microenvironment setting ${ }^{3}$ in academia to the detriment of a comprehensive understanding of the mechanisms of macroenvironment intervention.

(2) What is the significance of the connection between microenvironment settings and macroenvironment sectors for policy and practice purposes?
While microenvironmental interventions and policies are important for practitioners and decision makers to demonstrate local obesity reduction efforts, it is also crucial that practice and policy leaders recognize that people may be unaware or unable to articulate the effect of the macroenvironment on them. There is a need to explore the interplay between microenvironment settings and macroenvironment sectors, dominant health discourses, and individual interpretations, reproductions and resistances to these dominant discourses to inform population health interventions that will appropriately address the complexities of both policy change and worldwide obesity trends. For instance, practitioners and decision makers could undertake macrolevel interventions such as food policies and municipal planning. ${ }^{12,14}$ Public health messaging could emphasize macroenvironmental influences on food and physical activity behaviours, raising people's awareness of and capacity to navigate these issues. ${ }^{30}$ Finally, research could seek to reveal how macroenvironment sectors (e.g. food industry practices) shape the microenvironment and illuminate the effects on population health. ${ }^{6,12}$ Addressing the lack of public recognition about the potentially significant role of macroenvironmental interventions may engender a critical mass of public support for population-level interventions, rather than individual-level interventions. Nonetheless, it is important that practitioners and decision makers consider the relevant local context when developing programs, interventions and policies, while understanding the current large focus placed on personal responsibility within current political realities.

\section{Conclusion}

Our results indicate that researchers should seek to better understand the complex interplay between microenvironmental and macroenvironmental factors while exploring how people interpret these levels relative to prevailing health and social discourses. Given the specific emphasis the study participants placed on microenvironmental factors such as socioeconomic barriers, the study findings will help practitioners and decision makers target interventions and policies within microenvironments. A strategic focus on these areas will help to guide micro- and macrolevel interventions overall, while ensuring that research and practice respond to the diversity of perceptions about physical activity, healthy eating and community environments.

\section{Acknowledgements}

Funding was provided by the Heart and Stroke Foundation of Canada [PG-070353] in partnership with the Canadian Institutes of Health Research [BEO85861], and from the Killam Research Fund at the University of Alberta [KRFcgCG 08/09]. The authors would also like to thank the reviewers of this manuscript for their thoughtful comments; these helped to strengthen the manuscript.

\section{References}

1. Ng $\mathrm{M}$, Fleming $\mathrm{T}$, Robinson $\mathrm{M}$, et al. Global, regional, and national prevalence of overweight and obesity in children and adults during 1980-2013: a systematic analysis for the Global Burden of Disease Study 2013. Lancet. 2014; 384(9945):77781. doi:10.1016/S0140-6736(14)60460-8.

2. Catford J. Chronic disease: preventing the world's next tidal wave - the challenge for Canada 2007? Health Promot Int. 2007;22(1):1-4. doi: 10.1093/heapro /dam005.

3. Field AE, Coakley EH, Must A, et al. Impact of overweight on the risk of developing common chronic diseases during a 10-year period. Arch Intern Med. 2001;161(13):1581-6. doi:10.1001/archinte .161 .13 .1581 .

4. Withrow D, Alter DA. The economic burden of obesity worldwide: a systematic review of the direct costs of obesity. Obes Rev. 2011;12(2):131-41. doi: 10.1111/j .1467-789X.2009.00712.x.

5. Swinburn B, Egger G, Raza F. Dissecting obesogenic environments: the development and application of a framework for identifying and prioritizing environmental interventions for obesity. Prev Med. 1999;29(6):563-70. doi:10.1006/pmed .1999 .0585 .

6. Sallis JF, Glanz K. Physical activity and food environments: solutions to the obesity epidemic. Milbank Q. 2009;87(1):12354. doi: 10.1111/j.1468-0009.2009.00550.x. 
7. Kumanyika SK, Obarzanek E, Stettler N, et al. Population-based prevention of obesity: the need for comprehensive promotion of healthful eating, physical activity, and energy balance:a scientific statement from American Heart Association Council on Epidemiology and Prevention, Interdisciplinary Committee for Prevention (formerly the expert panel on population and prevention science). Circulation. 2008;118(4):428-64. doi: 10.1161 /CIRCULATIONAHA.108.189702.

8. Story M, Kaphingst KM, Robinson-O’Brien R, Glanz K. Creating healthy food and eating environments: policy and environmental approaches. Annu Rev Public Health. 2008; 29:253-72. doi: 10.1146 /annurev.publhealth.29.020907.090926.

9. Slater J, Green C, Sevenhuysen G, O’Neil J, Edginton, B. Socio-demographic and geographic analysis of overweight and obesity in Canadian adults using the Canadian Community Health Survey (2005). Chronic Dis Can. 2009;30(1):4-15.

10. Nguyen DM, El-Serag HB. The epidemiology of obesity. Gastroenterol Clin North Am. 2010; 39(1):1-7. doi: 10.1106/j.gtc .2009.12.014.

11. McLeroy KR, Bibeau D, Steckler A, Glanz K. An ecological perspective on health promotion programs. Health Educ Q. 1988;15(4):351-77. doi: 10.1177 /109019818801500401.

12. Kirk SF, Penney TL, McHugh TL. Characterizing the obesogenic environment: the state of the evidence with directions for future research. Obes Rev. 2010;11(2):109-17. doi: 10.1111/j.1467 -789X.2009.00611.x.

13. Popkin BM, Duffey K, Gordon-Larsen P. Environmental influences on food choice, physical activity and energy balance. Physiol Behav. 2005;86(5):603-13. doi: 10.1016/j.physbeh.2005.08.051.

14. Ashe M, Feldstein LM, Graff S, Kline R, Pinkas D, Zellers L. Local venues for change: legal strategies for healthy environments. J Law Med Ethics. 2007;35(1):138-47. doi: 10.1111/j.1748 $-720 X .2007 .00118 . x$.

15. Kramer L, Schwartz P, Cheadle A, et al. Promoting policy and environmental change using photovoice in the Kaiser Permanente Community Health Initiative. Health Promot Pract. 2010;11(3):332-9. doi: $10.1117 / 1524839909341555$.
16. Nykiforuk CI, Schopflocher D, Vallianatos $\mathrm{H}$, et al. Community health and the built environment: examining place in a Canadian chronic disease prevention project. Health Promot Int. 2013;28(2):25768. doi: 10.1093/heapro/dar093.

17. Wang C, Burris MA. Photovoice: concept, methodology, and use for participatory needs assessment. Health Educ Behav. 1997;24(3):369-87.

18. Wang CC, Morrel-Samuels S, Hutchison PM, Bell L, Pestronk RM. Flint Photovoice: community building among youths, adults, and policymakers. Am J Public Health. 2004;94(6):911-3.

19. Town of Bonnyville. Town of Bonnyville official final 2009 census results [Internet]. Bonnyville (AB): Town of Bonnyville; 2009 [cited 2015 Nov 12]. Available from: http://town.bonnyville.ab.ca/index.php /business-in-bonnyville/statistics -demographics/bonnyville-in-profile

20. Town of St. Paul. Welcome to the Town of St. Paul [Internet]. St. Paul (AB): Town of St. Paul; 2015 [cited 2015 Nov 12]. Available from: http://www.town.stpaul. ab.ca/

21. City of Edmonton. 2009 municipal census results [Internet]. Edmonton (AB): City of Edmonton; 2009 [cited 2015 Nov 12]. Available from: http://www.edmonton. ca/city_government/2009-municipal -census-results.aspx

22. City of Medicine Hat. City of Medicine Hat 2009 census: final report [Internet]. Medicine Hat $(\mathrm{AB})$ : City of Medicine Hat; 2009 [cited 2015 Nov 12]. Available from: http://www.medicinehat.ca/modules /showdocument.aspx?documentid $=276$

23. Raine KD, Plotnikoff R, Nykiforuk C, et al. Reflections on community-based population health intervention and evaluation for obesity and chronic disease prevention: the Healthy Alberta Communities project. Int J Public Health. 2010;55(6):679-86. doi:

$10.1007 / \mathrm{s} 00038$ $-010-0187-7$

24. Nykiforuk CI, Vallianatos H, Nieuwendyk LM. Photovoice as a method for revealing community perceptions of the built and social environment. Int $\mathrm{J}$ Qual Methods. 2011;10(2):103-24.
25. Hennessy E, Kraak VI, Hyatt RR, et al. Active living for rural children: community perspectives using PhotoVOICE. Am J Prev Med. 2010; 39(6):537-45. doi: 10.1016/j.amepre.2010.09.013.

26. Ferreira I, van der Horst K, Wendel-Vos W, Kremers S, van Lenthe FJ, Brug J. Environmental correlates of physical activity in youth - a review and update. Obes Rev. 2007;8(2):129-54.

27. Dean JA, Elliott SJ. Prioritizing obesity in the city. J Urban Health. 2012; 89(1):196213. doi: 10.1007/s11524-011-9620-3.

28. Deehr RC, Shumann A. Active Seattle: achieving walkability in diverse neighborhoods. Am J Prev Med. 2009;37(6):S40311. doi: 10.1016/j.amepre.2009.09.026.

29. Henson S, Blandon J, Cranfield J. Difficulty of healthy eating: a Rasch model approach. Soc Sci Med. 2010;70(10):157480. doi: 10.1016/j.socscimed.2010.01.037.

30. French SA, Story M, Jeffery RW. Environmental influences on eating and physical activity. Annu Rev Public Health. 2001;22:309-35. 